\title{
A língua portuguesa pelo cinema brasileiro: uma proposta de ação no ensino da língua portuguesa na educação de jovens e adultos
}

\author{
Marcelo Vicentin* \\ Jackeline Rodrigues Mendes** \\ Isabel Cristina dos Santos Rodrigues ${ }^{* * *}$ \\ Carlos Roberto da Silveira***
}

\begin{abstract}
Resumo
Este artigo problematiza o ensino de Língua Portuguesa na Educação de Jovens e Adultos por meio do cinema produzido e falado em português brasileiro. Utilizamos de pesquisa documental e histórica para, inicialmente, analisar a construção da língua brasileira, a proposta curricular do Estado de São Paulo e o projeto "O Cinema Vai à Escola" para, posteriormente, desestabilizar o encontro entre variedades linguísticas de maior prestígio língua escolar, escrita, oficial, padrão - e de menor prestígio - língua falada, cotidiana, coloquial, não padrão pelo e no audiovisual, a fim de observar olhares e falares sobre o português brasileiro, problematizando suas diferenças e preconceitos.

Palavras-chave: Educação de jovens e adultos; Cinema; Língua portuguesa; Subjetividade.
\end{abstract}

\section{The portuguese language for brazilian cinema: a proposal for action in education of portuguese language in youth and adult education}

\begin{abstract}
This article problematizes the teaching of Portuguese Language in the Education of Young and Adults by the film produced and spoken in Brazilian Portuguese. We used documentary and historical research to analyze the construction of the Brazilian language, the curricular proposal of the State of São Paulo and the project "Cinema Goes to School" to destabilize the encounter between linguistic varieties most prestigious - school language, writing, official, standard - and varieties less prestigious - spoken language, ordinary, colloquial, nonstandard by and in the audiovisual sector, in order to observe and speak about Brazilian Portuguese, problematizing their differences and prejudices.
\end{abstract}

Keywords: Youth and adult education; Movies; Portuguese language; Subjectivity.

\section{Cenas iniciais}

A Educação de Jovens e Adultos (EJA) apresenta muitas diferenças entre seus matriculados: geracionais, de gênero, geográficas, sociais, culturais etc.; no mesmo espaço convivem adolescentes, jovens, adultos e idosos; homens, mulheres, homossexuais; pessoas dos mais diferentes estados do país; de diferentes concepções religiosas, gostos musicais etc. Em comum a proximidade econômica, pertencentes aos grupos de menor poder financeiro, e a crença de que não sabem falar e escrever corretamente a língua portuguesa falada e escrita no Brasil.

A diversidade da EJA a torna um espaço de conflitos que a obriga a alteridade, a um viver em comum, a observar o espaço escolar de modo diferenciado ao(s) do(s) grupo(s) a que pertence(m). Para os mais jovens, geralmente, a EJA advém do abandono dos estudos em algum determinado momento, seja pela necessidade de uma ocupação financeira para auxiliar a família, ou para os

\footnotetext{
*Endereço eletrônico: marcelovicentin@yahoo.com.br

** Endereço eletrônico: rodrigues@ mpc.com.br
}

menores de idade, pela obrigatoriedade em frequentar a escola até alcançar a maioridade. Entre adultos e idosos, auxiliar a família financeiramente, a falta de oportunidade em prosseguir os estudos pela ausência ou proximidade de escolas, e, particularmente para as mulheres, o machismo dos pais impede a continuidade dos estudos por já terem conhecimento básico dos números e da escrita e leitura.

Os que não conseguem se adaptar as diferenças tendem a desistir temporária ou definitivamente da escola. $\mathrm{O}$ grupo de adultos e idosos dificilmente abandona a escola; contudo, o de jovens tende a apresentar um alto número de faltas e, consequentemente, o abandono do espaço escolar, seja pela possibilidade de um emprego melhor que o impossibilite de frequentar as aulas, o desinteresse ou o simples fato de alcançar a maioridade.

Com essa diversidade de grupos que atravessam o espaço escolar, em diferentes modos e ritmos, com choques mais acentuados em alguns

\footnotetext{
*** Endereço eletrônico: isaisabelrodrigues@ gmail.com

**** Endereço eletrônico: carlosilveir@yahoo.com.br
} 
momentos, a sala de aula se torna um espaço de alteridade, colocando em evidência um componente não curricular: aprender a conviver. Se diferentes identidades, falares do português podem conviver, os diferentes campos do cinema e da educação também o podem, provocando, através desse encontro, lugares e olhares outros.

Para tanto, não nos preocupamos em inventariar a variedade padrão da língua portuguesa falada e escrita no Brasil nem desenvolver um histórico de suas transformações. Pretendemos apenas perceber embates na construção da língua e de sua norma-padrão, visto que refletem sobre o mito do desconhecimento e do falar a língua materna. Embates estes que se relacionam com a questão identitária em torno do Estado-Nação brasileiro, atravessado pela construção de uma unidade linguística.

$\mathrm{Na}$ sequência, observamos a inserção de práticas culturais articuladas a competências curriculares por meio da proposta curricular do Estado de São Paulo e do projeto O Cinema Vai à Escola, que buscou incorporar e articular a linguagem cinematográfica como ferramenta de apoio para o trato de assuntos complexos e difíceis para o universo escolar. Também observamos o cinema como objeto artístico, potência transgressora e de resistência cultural, a fim de (re)significar conceitos estabelecidos pelo imenso campo de representações e de possibilidades para a organização e socialização do mundo; de dizer o mundo, deslocando e desestabilizando o olhar do espectador para um encontro com si e com o outro, com a alteridade; provocando o diálogo entre diferentes línguas e vozes.

\section{Momentos de uma língua}

Antes da invasão e dominação portuguesas nas terras que vieram a ser conhecida como Brasil, uma miríade de línguas eram faladas por seus habitantes. A língua mais comum à região costeira pertencia ao tronco linguístico do tupi-guarani; língua que os jesuítas esquadrinharam, sistematizaram e enquadraram em modelos gramaticais e linguísticos europeus. É nesse momento que emerge o que hoje é conhecido como nheengatu ${ }^{1}$ ou língua geral, uma mistura do tupi com o português, que não é tupi tampouco português, uma língua miscigenada, da união entre portugueses e europeus, uma língua mameluca.

Enquanto o Brasil não se transformou em objeto de profundo interesse da Coroa portuguesa, a língua geral foi o idioma dominante por mais de 200 anos. O nheengatu, que era a língua oficial, teve seu uso e ensino proibidos em 1758. Seus principais precursores, os jesuítas, foram expulsos das terras brasileiras em 1759. Essas decisões do Marquês de Pombal oficializaram o português falado e escrito em Portugal, língua do Império, como língua oficial do Brasil, proibindo o ensino de qualquer outra língua diferente.

Com a fuga da família real portuguesa para o Brasil e, em decorrência, com a ampliação urbana da cidade do Rio de Janeiro - a Corte em terras brasileiras - ampliou-se o número de escolas, efetivou-se o aparelho burocrático-estatal, além de surgirem as primeiras bibliotecas e imprensa, consolidou-se a presença do português de Portugal no Brasil. O que não impediu de uma cultura oral, uma língua do cotidiano, aprendida nas relações sociais, ser muito mais presente na sociedade brasileira, visto a imensidão territorial brasileira, os diferentes grupos étnicos, e o pouco acesso a uma educação escolarizada destinada para uma pequena elite presente nestas terras.

Com a independência de Portugal, muito superficialmente se alteraram as circunstâncias políticas, mantendo-se o Brasil um Estado absolutista. Contudo com a ruptura institucional entre a Metrópole e a Colônia houve a necessidade de inventar, de construir uma identidade diferente que distinguisse o brasileiro do português. Para tanto, necessitou-se inventar um mito fundador a fim de legitimar e naturalizar uma origem, uma identidade. Identidade esta, como observado por Berenblum (2003), construída da tensão entre a raiz portuguesa, símbolo da superioridade da civilização europeia, e as raízes indígenas e negras. Uma identidade que apresentasse particularidades do homem brasileiro e ao mesmo tempo a diferença e a continuidade da civilização ocidental.

Essa ambiguidade presente na construção do mito nacional também atravessou a construção de uma língua "brasileira". Para alguns a unidade deveria ser mantida, para outros uma liberdade idiomática como condição para a construção de uma identidade e a afirmação de uma literatura: uma língua orientada por uma determinada "fala brasileira" ou orientada pela escrita portuguesa. Tal qual a criação do mito nacional, a construção da Língua-Mãe manteve a tensão presente nos dois polos: uma dicotomia ainda presente no mito de que no Brasil o brasileiro desconhece sua língua e não a fala corretamente. 


\section{Homogeneizando a língua}

Inventar uma unidade linguística, uma língua oficial - tal qual a invenção de uma Nação -, a fim de homogeneizar culturalmente uma sociedade heterogênea, determina, obrigatoriamente, a invenção de uma gramática e a sua difusão pelo sistema escolar: um processo de objetivação de identidades. Por conseguinte, a invenção e a institucionalização de uma língua oficial automaticamente transformam as demais variedades em não oficiais, em dialetos, estigmatizando-as como marginais. Como não existem memórias universais, a decretação de uma Língua-Mãe promove silêncios sobre diversas e diferentes memórias; vozes e línguas.

Esse processo atravessou o conceito de Estado-Nação proposto pela Modernidade, sendo um elemento comum na criação de todas as línguas que se institucionalizaram nesse momento particular: a língua como dispositivo essencial para a constituição de uma identidade nacional. A consolidação desse processo necessitou de um sistema um ensino que atendesse a um número maior de pessoas, falantes ou não do idioma, a fim de desenvolver certa unidade identitária dos Estados-Nações. Como observado por Berenblum (2003), isso contribuiu para o surgimento, no interior das sociedades, não apenas de uma ilusão homogeneizadora, mas de uma profunda desigualdade, constituindo-se em mecanismo de exclusão e segmentação.

O sistema linguístico de um país não se constitui apenas de uma única variedade, mas por um conjunto amplo, complexo e contingente. O que os diferencia é a institucionalização de uma em detrimento de todas as demais variedades. Uma, a institucional, representa a norma-padrão e o seu domínio é sinônimo de prestígio; outra, a vulgar, a língua bárbara, representa a marginalização e a exclusão social.

A estruturação de uma norma-padrão para a língua é atravessada por relações de poder, que têm seu aspecto mais visível através das gramáticas que se baseiam em um cânone literário determinado por instituições e profissionais que exercem um controle a fim de mantê-la em um bom, correto, civilizado e elegante caminho. A norma-padrão se constitui em um conceito hegemônico ${ }^{2}$, uma construção a partir de alianças e do uso de meios ideológicos para manter relações de domínio e subordinação. Desse modo, determinados grupos sociais que detenham um maior peso político e econômico, produzem e regem as normas de uma língua que se organiza como variedade linguística oficial.

É uma norma [...] imposta de cima para baixo, decretada por pessoas e instituições que tentam regrar, regular e regulamentar o uso da língua. $\mathrm{E}$ é também um padrão: um modelo artificial, arbitrário, construído segundo critérios de bom gosto, vinculados a uma determinada classe social, a um determinado período histórico e num determinado lugar (BAGNO, 2010, p.65).

Uma variedade linguística institucionalizada, tal qual a qualquer sistema de formação identitário, é atravessada por relações de poder que constroem e impõem significados sobre o mundo social. Para Bagno (2003), se tomarmos como exemplo uma linha que liga dois extremos, quanto mais próximo da variedade culta, maior a possibilidade de inclusão em um grupo de maior prestígio no mundo social; quanto mais próximo de uma variedade de menor prestígio, de uma língua bárbara, maior a possibilidade de inclusão em um grupo marginalizado. Por conseguinte, o preconceito linguístico é um preconceito social em que se discrimina o modo de falar da pessoa, sob a acusação de falar tudo errado, de não saber o português.

Novos projetos educacionais, ao priorizarem uma educação de qualidade e uma educação para a formação cidadã, valorizam outros cânones de padrões culturais, considerando-os parte de uma cultura comum, nacional, e entre eles a língua escrita e falada.

\section{Objetos culturais na nova proposta curricular para a rede escolar paulista}

A proposta curricular do Estado de São Paulo, organizada entre os anos de 2008 e $2010^{3}$, tem a percepção de que o Contemporâneo apresenta desafios que ainda não são contemplados no mundo escolar, objetivando, assim, apresentar soluções que tornem as escolas capazes de prepararem os alunos para o momento e as pressões decorrentes. Para tanto, procura construir outra identidade para a escola e o currículo a fim de enfrentar o desafio proposto.

Este documento apresenta os princípios orientadores do currículo para uma escola capaz de promover as competências indispensáveis ao enfrentamento dos desafios sociais, culturais e profissionais do mundo contemporâneo. 
Contempla algumas das principais características da sociedade do conhecimento e das pressões que a contemporaneidade exerce sobre os jovens cidadãos, propondo princípios orientadores para a prática educativa, a fim de que as escolas possam preparar seus alunos para esse novo tempo. Ao priorizar a competência de leitura e escrita, o Currículo define a escola como espaço de cultura e de articulação de competências e de conteúdos disciplinares (SÃO PAULO, 2010, p. 7).

A proposta curricular enfatiza que a sociedade faz uso intensivo do conhecimento primordialmente pelo uso das tecnologias da comunicação a fim de organizar a vida social e cidadã, gerando novas formas de exclusão material e cultural. Percebe também a existência de uma multiplicidade de identidades presentes na organização social, e para que os conflitos possam ser atenuados, faz-se necessário um processo de democratização e inclusão escolar.

Fundamentada nas recomendações dos Parâmetros Curriculares Nacionais (PCN), nas normas das Diretrizes Curriculares Nacionais (DCN) e, primordialmente, nos dispositivos presentes na Lei de Diretrizes e Bases da Educação Nacional (LDB), a proposta observa que a educação proporciona a inclusão ou exclusão de grupos sociais, além de torná-lo crítico e capaz da prática do exercício da cidadania, que é definido como uma ação de "construir identidade, agir com autonomia e em relação com o outro, bem como incorporar a diversidade, $[\ldots$ base $]$ de responsabilidade, [essencial] para a inserção cidadã nas dimensões sociais e produtivas" (SÃO PAULO, 2010, p.10). Para tanto, a proposta curricular vincula a escola ao mundo do trabalho e às práticas sociais, observando prioridades para a competência da leitura e da escrita por meio da língua materna em diferentes situações de discurso, e a produção textual; também a escola como espaço de cultura, tornando curriculares os momentos artísticos e culturais, antes extracurriculares.

Ao observar o currículo como espaço de presença e construção cultural, objetivou-se romper com a disjunção existente entre cultura e conhecimento na escola, possibilitando que conhecimentos diversos surjam desse encontro entre movimentos culturais e práticas pedagógicas, proporcionando que atividades antes contextualizadas como fora do currículo ou extracurriculares sejam tomadas como curriculares, a fim de:
Democratizar o acesso de professores e alunos da rede pública estadual a equipamentos, bens e produções culturais que constituem patrimônio cultural da sociedade, tendo em vista uma formação plural e a inserção social.

Fortalecer o ensino por meio de novas formas e possibilidades de desenvolvimento dos conteúdos curriculares em articulação com produções socioculturais e fenômenos naturais, diversificando-se as situações de aprendizagens (SÃO PAULO, 2015).

Desse modo, a proposta curricular propôs promover através do programa Cultura é Currículo ${ }^{4}$, a inserção curricular de práticas culturais articulando-as a competências curriculares, a fim de promover cidadania cultural $^{5}$. Como parte da proposta, o projeto O Cinema Vai à Escola propõe integrar a linguagem cinematográfica ao currículo.

\section{Cinema e escola}

Desde os anos 10, do século XX, que a educação brasileira procura estabelecer uma relação entre cinema e escola. Contudo, somente quando o pensamento da Escola Nova se encontrou com a política de Getúlio Vargas, culminado com a criação do Instituto Nacional de Cinema Brasileiro (INCE), em 1936, essa relação se consolidou. O INCE estabeleceu parâmetros para uma forma de cinema que apresentava possibilidades de combater e erradicar a ignorância ao alcançar as populações carentes e menos escolarizadas, tomando-o como a escola "dos que não têm escolas, pois [... vai] aos que não sabem ler, constituindo-se, por vezes, no único meio de transmissão da arte, da ciência e da técnica" (MORETTIN, 1995, p.16), espalhando pelo país o saber letrado e o conhecimento científico.

Entre silêncios e projeções canceladas, a atual proposta curricular paulista, ao retomar a parceria entre cinema e educação, para além do saber letrado e do conhecimento científico, procura, ao associar os meios e as mídias artísticas ao currículo escolar, desenvolver conhecimentos práticos e estéticos sobre o cinema por meio de uma gama de filmes, a fim de promover a discussão de aspectos gerais sobre a vida e o mundo, bem como aprimorar o senso crítico-reflexivo de professores e alunos.

França (2005) observa que o cinema carrega em si discussões sobre fronteiras, pertencimento, cultura, identidade, discursos dissidentes a um 
hegemônico, mostrando seus desajustes e rachaduras. Desse modo, em consonância com o parágrafo segundo, do artigo 35 da $\mathrm{LDB}^{6}$, a presença do cinema pode tornar mais interessante $o$ tratamento de conteúdos curriculares, ou seja, motivar o aluno para que, dentro do espaço e da perspectiva escolar, reflita criticamente sobre o mundo que o cerca.

Professores e alunos pertencem a um mundo sobre o qual devem refletir e compreender, um mundo de "assuntos delicados e complexos como preconceito, violência, exclusão social, sexualidade, injustiças, entre tantos outros, [que] fazem parte do cotidiano dos jovens e de seus professores que, como todos nós, têm dificuldades de lidar com eles". (CASTRO, 2008, p.3). E a presença do cinema no âmbito escolar produz possibilidades de articulação entre o currículo oficial com temas tão presentes e prementes ao momento, com o uso de filmes auxiliando a inclusão do discurso escolar no mundo contemporâneo.

Stam e Shohat (2005) comentam que por mais que haja uma cultura hegemônica, ela tem de dialogar e coexistir com culturas locais, a qual, ao ser absorvida, se transfigura, proporcionando que culturas diferentes ganhem projeção através de uma língua franca cultural. As novas tecnologias de captação e reprodução de imagens e as mudanças nos modos distribuição e exibição de filmes, pelos avanços na telecomunicação, modificam e proporcionam espaços para o diálogo entre as diferentes culturas e povos. Espaços para discursos diferentes que possibilitam observar mundos em que (co)habitam outras culturas e civilizações, diferentes modos de viver, falar, existir e pensar. Possibilita que a alteridade, o outro ganhe espaço fora e dentro das telas.

\section{Projetando dizeres, histórias e experiências}

Trabalhar com o ensino da Língua Portuguesa, para nós, é valorizar os modos como de falar, os sotaques, valorizando a pessoa e o respeito pelos diferentes modos de se utilizar a Língua-Mãe. Entretanto quanto maior o prestígio econômico, político, social, cultural, educacional, maior a intolerância com aqueles que se utilizam, de variedades menos prestigiadas e estigmatizadas. "Numa época em que a discriminação em termos de raça, cor, religião, ou sexo não é publicamente aceitável, o último baluarte da discriminação social explícita continuará a ser o uso que uma pessoa faz da língua” (MILROY apud BAGNO, 2010, p.13).
Pela língua possibilitamos às pessoas e as suas personagens poderem representar seus dramas e histórias, que suas vozes possam contar seus dramas e comédias vividas. Filmes no espaço escolar promovem risos, choros, discussões, comentários e histórias que os alunos dividem com outros alunos e professores. Memórias esquecidas ou que se queiram esquecidas retornam. Os alunos se permitem, permitindo aos outros suas memórias, cenas de uma infância feliz para uns, outros nem tanto; os relacionamentos, os amores, as decepções. Histórias aparecem e ganham forma e, como um filme, são sobre nós projetadas.

Seja pelo texto ou pelo filme, busca-se movimentar as experiências, degustar acontecimentos, tensionar a corda ${ }^{7}$, provocando singularidades, avançando sobre fronteiras, a fim de exercitar a alteridade, trazendo à discussão outros modos de perceber/ser percebido pela língua que falamos e escrevemos. $O$ filme como um acontecimento $^{8}$, trabalhando sob/sobre a tensão de relações de força e poder presentes em uma língua que se quer hegemônica; que separa, distingue, isola; a língua pela qual nos dizemos e somos ditos.

As mais diferentes mídias produzem estereótipos atravessados por situações econômicas e sociais de miséria e fome, alcançando modos de uso da língua e um saber letrado. Por meio de produções audiovisuais podemos por em discussão esses saberes e estereótipos, como por exemplo, em Narradores de Javé, de Eliane Caffé 9 , um drama, em tom de comédia, que trata sobre os valores culturais presentes em uma língua, bem como dos valores entre a língua oral e a língua escrita; ou em filmes de Eduardo Coutinho, que deixa a câmera e o microfone aberto para os seus entrevistados, apresentando uma ampla gama de falares e existir.

O sotaque é a marca da diferença, o elemento que destrói a aparente igualdade inicial e ativa no interlocutor todo um mecanismo de representações e associações acerca de quem é esse outro, diferente, estranho, estrangeiro. [...] A língua é um símbolo de identidade (talvez o mais poderoso) que nos permite reconhecermos como naturais de uma cidade, de um país e ao mesmo tempo, identificar quem não o é. [...] A pronúncia correta pode converter o amigo em inimigo ou vice-versa (BERENBLUM, 2003, p.20).

Os filmes brasileiros nos permitem uma variedade de modos e situações de uso da língua pelos mais diferentes grupos, sejam geracionais, de 
gênero, geográficos, sociais, culturais etc., proporcionando aos alunos e aos professores se exporem, traduzirem os significados de seus códigos e condutas, sobre diferentes e múltiplos assuntos possibilitando a reflexão e o reconhecimento das diferenças linguísticas e da diversidade social brasileira. De ao se dizerem e serem ditos, transgredirem seus papeis, suas posições-sujeito, permitindo-se ao não esperado, intercedendo em prol do novo, construindo experiências, transformações; vivenciando e compartilhando acontecimentos, pois somente que os vive pode compartilhar com outros.

De acordo com Fischer (2012), os objetos artísticos, como o cinema, interferem, incomodam, perturbam a rigidez das representações, promovendo fissuras e espaços para novos olhares, novas palavras, novos significados, agindo sobre apagamentos e exclusões de pessoas que desapareceriam - como os estigmatizados alunos da EJA -, mas que fixadas em narrativas se tornaram novamente visíveis; histórias que movimentam histórias de vida e morte, carregadas de beleza e assombro. Situação que Foucault (2003) problematizou sobre pessoas indesejadas, sujeitos infames que vão sendo apagados, porém transformados em texto, têm o direito a palavra, de dizer e serem ditos, passam a serem novamente percebidos pelo corpo social, ganhando visibilidade.

\section{Cenas finais de um filme sem fim}

Odin (2005) argumenta que a escola é um dos poucos lugares, por sua estrutura impositiva, que podem promover o "modo de $\operatorname{ver}^{10 "}$ documentário, ou seja, o controle das subjetividades, por interferir no sentimento de agenciamento, na percepção de sentidos e afetos, dificultando a possibilidade de outros "modos de ver" descritos por ele, como o espetacular, o argumentativo/persuasivo, o ficcionalizante, o energético etc. Para o autor "existem sempre diferentes públicos, e um mesmo indivíduo espectador se encontra sempre no ponto de encontro de diferentes públicos e, portanto, de diferentes modos de produção de sentido que ele mobilizará simultânea ou sucessivamente" (ODIN, 2005, p.45).

Ao excluirmos possibilidades, "modos de ver", produzimos exclusões que organizam o mundo pedagógico, alimentando um determinado discurso hegemônico, como a norma-padrão da língua, um "modo como o saber é aplicado em sociedade, como é valorizado, distribuído, repartido e de certo modo atribuído" (FOUCAULT, 2011, p.17). Uma escola que se diz cidadã deve estar atenta para uma educação inclusiva, a fim de diminuir o processo de exclusão, observando as diferenças e, para tanto, não deve pressupor apenas uma unicidade identitária.

O exercício da diferença é um exercício de convivência, quanto mais nos aproximamos de outras representações, mais avançamos sobre fronteiras espaciais outrora construídas, mais quebramos estereótipos e preconceitos, como os associados aos usos da língua materna. Ao acomodar a diferença em seu corpo, a escola permite construir e discutir identidade(s), permitindo ser e pertencer. Promover a diferença é exercitar conflitos, contradições, uma educação poética cujo "modo de existir é interpretando e traduzindo. Portanto, educador e educando tomam o dito, o texto, e o voltam a dizer, o leem o interpretam, o traduzem, se desdizem dele, o redizem de outro modo... e assim até o final, até a morte" (MÈLICH, 2011, p. 280).

A experiência cinematográfica é uma experiência estética que permite olharmos para o mundo e para nós, atravessando e movimentando nossas identidades, nossas memórias. Ao assistir um filme podemos produzir sentidos sobre nós e sobre o mundo. Por conseguinte, o cinema, consolidado como entretenimento no imaginário popular e a disseminado pelas diferentes esferas sociais, ao encontrar-se com o universo escolar pode promover a construção de um juízo crítico-estético, contudo nunca deve ser esquecido que essa prática, ao mesmo tempo, entretenha, motive, divirta; promova interpretações, conflitos, contradições.

Cinema e escola tensionando as relações de poder, as relações de alteridade entre diferentes e diferenças - uma Babel outra à bíblica, híbrida, múltipla, em que o institucionalizado e bárbaro se chocam -, podem provocar faíscas que afetem "a representação acerca das línguas nacionais como símbolo de identidade nacional [... possibilitando o surgimento de] novas formas de pensar a diversidade, $[\ldots$ de reconhecer] a autenticidade de outras vozes e as diferenças [para que pareçam] estar no centro da atenção" (BERENBLUM, 2003, p.101-2).

Ao incorporarem-se outras narrativas se possibilita histórias em línguas outras, abrangentes e diversificadas. Contudo, se a história que a LínguaMãe e o Estado-Pai contarem for única, uniforme, homogênea e hegemônica, símbolo de identidade e de unidade nacional, tomando todos como iguais, 
integrando, nivelando seus saberes e suas línguas, privilegiando uns, silenciando outros, teremos, novamente, silêncio e marginalização. Outrossim, se escolherem caminhos múltiplos, heterogêneos, híbridos, possibilitando a pluralidade de visões de mundo que circulam e constituem os diferentes sujeitos do espaço escolar, outras significações, outras identidades, outras personagens através de discursos ordinários e cotidianos contrapostos ao discurso hegemônico e a língua obrigatória, não haverá um fim, nem um final igual para todos. Afinal, o que é real, o que é verdade, senão o vivido.

\section{Notas}

1 Fala boa.

$2 \mathrm{O}$ poder sobre a sociedade como um todo de uma das classes economicamente definidas como fundamentais em aliança com outras forças sociais, mas nunca atingido senão parcial e temporariamente, como um 'equilíbrio instável'. Hegemonia é a construção de alianças e a integração muito mais do que simplesmente a dominação de classes subalternas, mediante concessões ou meios ideológicos para ganhar seu consentimento. Hegemonia é um foco de constante luta sobre pontos de maior instabilidade entre classes e blocos para construir, manter ou romper alianças e relações de dominação/subordinação que assume formas econômicas, políticas e ideológicas. A luta hegemônica localiza-se em uma frente ampla, que inclui as instituições da sociedade civil (educação, sindicatos, família), com possível desigualdade entre diferentes níveis e domínios (FAIRCLOUGH, 2008, p. 122).

3 Em 2010, na gestão do Secretário de Educação, Paulo Renato de Souza, foi publicada a versão definitiva dos documentos curriculares da nova proposta curricular do estado de São Paulo. A primeira versão foi publicada, em 2008, durante a gestão de Maria Helena Guimarães de Castro.

4 Programa criado em 2008, pela Secretaria Estadual de Educação (SEE-SP), complementar à nova proposta curricular paulista.

5 Currículo do Estado de São Paulo, 2010, p.11.

$6 \mathrm{O}$ aprimoramento do educando como pessoa humana, incluindo a formação ética e o desenvolvimento da autonomia intelectual do pensamento crítico.

7 De Certeau (2009) comenta que por trás dos bastidores da educação, há cordões invisíveis que "manipulam" o processo de encenação, porém há uma contrapartida, um tensionamento sobre esses fios, denominados de procedimentos minúsculos ou cotidianos. Consequentemente, como espaço de disputa na produção de significados, o outro, as diferenças trazem para o campo escolar estas tensões minúsculas, cotidianas, microfísicas, por meio de questões que os movimentam, o que possibilita o surgimento de outras produções discursivas, diferentes àquelas dominantes possam emergir.

8 Para Larrosa (2011) acontecimento é algo indeterminado, aquilo que não pode previsto, logo identificado ou compreendido; movimento de libertação de um passado e abertura pra um porvir; o acontecimento é a interrupção, a novidade, a surpresa.

9 Narradores de Javé. Direção de Eliane Caffé. Produção de Vânia Catani, Caio Gullane, Fabiano Gullane, André Montenegro. São Paulo: Videofilmes, 2003, DVD (102 min.). Sonoro, color. Português. Legendas em Francês, Inglês e Português.

10 A produção de sentidos a partir de fatos que indiquem um domínio categorial, algo pertencente a um espaço histórico-cultural comum.

\section{Referências}

BAGNO, M. Preconceito linguístico: o que é, como se faz. 22. ed., São Paulo: Loyola, 2003.

. A norma culta: língua e poder na sociedade brasileira. 1. ed., 8. reimp., São Paulo: Parábola, 2010.

BERENBLUM, A. A invenção da palavra oficial: identidade, língua nacional e escola em tempos de globalização. Belo Horizonte: Autêntica, 2003.

BRASIL. Lei 9.394 de 20 de dezembro de 1996. Lei de diretrizes e bases da educação nacional. Brasília, DF, 1996.

CASTRO, M. H. G. O cinema vai à escola para ampliar o currículo. In: DEVANIL T. et al. (Orgs.) Caderno de cinema do professor: um. São Paulo: FDE, 2008, p.3-4.

De CERTEAU, M. A invenção do cotidiano: artes de fazer. Tradução Ephraim Ferreira Alves. 16. ed. Petrópolis: Vozes, 2009.

FAIRCLOUGH, N. Discurso e mudança social. Tradução Isabel Magalhães. Brasília: UnB, 2008.

FISCHER, R. M. B. O visível e o enunciável: contribuições do pensamento foucaultiano aos 
estudos de comunicação. In: FISCHER, R. M. B. Trabalhar com Foucault: arqueologia de uma paixão. Belo Horizonte: Autêntica, 2012, p. 133146.

Quando os meninos de Cidade de Deus nos olham. In: FISCHER, R. M. B. Trabalhar com Foucault: arqueologia de uma paixão. Belo Horizonte: Autêntica, 2012a, p. 147-154.

FOUCAULT, M. A vida dos homens infames. In: MOTTA, M. B. (Org.) Ditos e escritos IV: estratégia, poder-saber. Tradução Elisa Monteiro, Inês A. D. Barbosa. Rio de Janeiro: Forense Universitária, 2003, p. 203-222.

. A ordem do discurso. Tradução Laura F. de A. Sampaio. ed. 21. São Paulo: Loyola, 2011

FRANÇA, A. Foucault e o cinema contemporâneo. Revista Alceu. Rio de Janeiro: v. 5, n. 10, jan.-jul. 2005, p.30-9. Disponível em: $<$ http://revistaalceu.com.puc-rio.br/media /alceu_n10_andrea.pdf>. Acesso em 08 ago. 2015.

FUSARI. J. C. A linguagem do cinema no currículo do ensino médio: um recurso para o professor. In: DEVANIL, T. et al. (Orgs.). Caderno de cinema do professor: três. São Paulo: FDE, 2009, p.33-45

LARROSA, J. Dar a palavra: notas para uma dialógica da transmissão. In: LARROSA, J.; SKLIAR, C. (Orgs.). Habitantes de Babel: políticas, poéticas da diferença. Tradução Semíramis G. da Veiga. Belo Horizonte: Autêntica, 2011, p.281-295.

MÈLICH, J. A palavra múltipla: por uma educação (po)ética. In: LARROSA, J.; SKLIAR, C. (Orgs.). Habitantes de Babel: políticas, poéticas da diferença. Tradução Semíramis G. da Veiga. Belo Horizonte: Autêntica, 2011, p.269-280.
MORETTIN, E. V. Cinema Educativo: Uma abordagem histórica. Comunicação e Educação. São Paulo: Moderna, n.4, p.13-19, set-dez. 1995.

ODIN, R. A questão do público: uma abordagem semiopragmática. In: RAMOS, F.P. (Org.). Teoria contemporânea do cinema, vol. II: documentário e narratividade ficcional. São Paulo: Senac, 2005, p.27-45.

SÃO PAULO. Apresentação do currículo do Estado de São Paulo. In: FINI, M. I.; VIEIRA, A. (Coords.). Currículo do Estado de São Paulo: linguagens, códigos e suas tecnologias. São Paulo: SEE, 2010, p.7-24.

- A concepção do ensino na área de linguagens, códigos e suas tecnologias. In: FINI, M. I.; VIEIRA, A. (Coords.). Currículo do Estado de São Paulo: linguagens, códigos e suas tecnologias. São Paulo: SEE, 2010, p.25-43.

SÃO PAULO. Cultura é Currículo. Disponível em: $<$ http://culturaecurriculo.fde.sp.gov.br/ programa.aspx>. Acesso em: set. 2015.

SOUZA, P. R. Carta do Secretário. In: FINI, M. I.; VIEIRA, A. (Coords.). Currículo do Estado de São Paulo: linguagens, códigos e suas tecnologias. São Paulo: SEE, 2010, p.3.

STAM, R; SHOHAT, E. Teoria do cinema e espectorialidade na era dos "pós". In: RAMOS, F.P. (Org.). Teoria contemporânea do cinema, vol. I: pós-estruturalismo e filosofia analítica. São Paulo: Senac, 2005, p.393-424.

VIANNA, B. O contrário da memória. Revista Piauí. Alvinegra: Rio de Janeiro. n. 116, mai. 2016. p.52-58.

\section{Sobre os autores}

Marcelo Vicentin: É doutorando em Educação Universidade São Francisco, bolsista Capes.

Jackeline Rodrigues Mendes: Docente da Faculdade de Educação, Universidade Estadual de Campinas.

Isabel Cristina dos Santos Rodrigues: Professora da Faculdades Zumbi dos Palmares.

Carlos Roberto da Silveira: Professor do Programa de Pós-Graduação Stricto Sensu em Educação, Prof. Dr. Universidade São Francisco.

Recebido em julho de 2016.

Aprovado em outubro de 2016. 